\title{
The first Summer Transportation Institute (STI) at the University of Puerto Rico: An experiment in motivating high school Puerto Ricans to study transportation related careers
}

\author{
Antonio A. González-Quevedo, Didier M. Valdés-Díaz, Freya M. Toledo-Feria \\ School of Engineering \\ University of Puerto Rico at Mayagüez
}

\begin{abstract}
The Civil Infrastructure Research Center (CIRC) of the University of Puerto Rico at Mayagüez (UPRM) managed the first Summer Transportation Institute at the University of Puerto Rico during the summer of 2001. The objective of this program was to expose a group of high school students to a variety of academic experiences designed to motivate them toward professions in the field of transportation. High school students soon to enter their Junior Year were eligible to participate on our first Summer Transportation Institute in Puerto Rico. The activities were very diverse and included two trips to San Juan, the capital city of Puerto Rico, each time with an overnight stay. Besides these and other day-long field trips, our institute provided class sessions in transportation related topics, as well as participatory working sessions for the students to develop their projects. The participants also learned to write technical reports and prepare presentations, and about opportunities to study and work in the areas related to transportation. A number of sports activities, competitions, and motivational activities complemented the academic activities.
\end{abstract}

Our institute was a complete success due in part to the enthusiastic support we received from National Summer Transportation Institute Resource Center, as well as from the University of Puerto Rico at Mayagüez administration at all levels. We also received support from the state and federal transportation agencies.

\section{2001 Summer Transportation Institute Organization}

The University of Puerto Rico, Mayagüez Campus (UPRM) served as the administrator of the first Puerto Rico Summer Transportation Institute (PR-STI). This STI was beneficial because it provided the opportunity to expose soon to be juniors in high school to a diverse group of transportation educators and professionals working in various modes of transport.

Primarily, the 2001 PR-STI emphasized both the benefits associated with a career in transportation as well as the education required to enter this important field. The PR-STI was designed to create an educational and training delivery system that: (1) attracted secondary school students to and enhance their interests in careers in transportation: (2) improved mathematics, science, and technology skills; and (3) through creative partnerships, strengthened 
the links between the transportation sector and our university. The PR-STI specifically focused on creating high interest among secondary school students by providing opportunities and activities that enhanced awareness and knowledge about transportation careers.

\section{A. Facts and Figures}

The Puerto Rico Summer Transportation Institute took place from June $25^{\text {th }}$ through July $20^{\text {th }}, 2001$ at the University of Puerto Rico, Mayagüez Campus. This non-residential institute had a diverse schedule, which incorporated a combination of lectures, hands-on exercises, and facility tours and activities. The Civil Infrastructure Research Center (CIRC) administered the program. Thanks to the dedicated job of all the staff at the CIRC, the program was very successful and well organized.

The theme for the 2001 PR-STI was Multimodal Transportation Systems. Dr. Didier M. Valdés-Díaz had overall responsibility of the project with Professor Freya M. Toledo-Feria as Director of the Academic Program, and Dr. Antonio A. González-Quevedo as Senior Advisor.

\section{B. Intermodal Advisory Committee}

An Intermodal Advisory Committee was selected by UPRM to support and advice the faculty. It was composed of 9 representatives from the institution, state and federal agencies, public transit properties, and professionals in transportation from the public and private sector. It was the responsibility of the Advisory Board to assist us in all aspects of the $2001 \mathrm{PR}-\mathrm{STI}$ as necessary and appropriate. They assisted with identifying speakers, coordinating field trips and tours, providing overall support and guidance in the development of the curriculum, their own participation as speakers, and the execution of the graduation ceremony.

\section{Program Faculty and Staff}

Faculty members and students from the University of Puerto Rico at Mayagüez assumed the key roles associated with the coordinating and hosting of the $2001 \mathrm{PR}-\mathrm{STI}$. The project director was responsible for all aspects of the project and served as the focus for project contact with the NSTI Resource Center. He also assisted in the development and implementation of all phases of the PR-STI, including the orientation, curriculum development, the graduation ceremony, and the evaluations of the program. The academic coordinator assumed the daily coordination of the PR-STI, including the preparation of the interim and final reports, the development and administration of the budget, the approval of personnel, the development, implementation, and evaluation of the academic program, and the supervision of academic staff and other speakers. Assistant academic coordinator was responsible for conducting academic instruction and related activities, interaction with the students and staff, and other duties associated with the execution of the PR-STI. The Senior Advisor provided general direction and guidance to the rest of the faculty and students. Academic aides were responsible for coordinating and overseeing activities, projects, and any other duties necessary for the daily operation of the program. 


\section{2001 PR-STI Participants}

The education of students in engineering and transportation, mathematics, and the sciences is crucial to supplying the future demand for highly qualified individuals in the scientific and technical fields. Thus, through the recruitment of high-quality students to participate in the $2001 \mathrm{PR}-\mathrm{STI}$, the institution worked to attract the best and brightest to the transportation profession.

Student recruitment for the 2001 PR-STI began late in April 2001. Students in $10^{\text {th }}$ grade who were starting their Junior Year in the following fall were targeted for program participation. Recruitment activities included, but were not limited to, PR-STI staff visiting local high school campuses, mailing of application materials to high school guidance counselors, and direct mailing of applications to students targeted by guidance counselors. Student selection was based on criteria such as grade point average, letters of recommendation, and a written essay. It was the intent of the project team to recruit approximately 20 students to participate in the program. Students selected to participate were notified by mail and received all the necessary forms for participating in the program.

\section{Academic Program}

The key component of the 2001 PR-STI was the academic program. The following sections provide a description of the objectives and development of the University of Puerto Rico at Mayaguiez program and the participants' evaluation of the program.

\section{A. Program Objectives}

The University of Puerto Rico at Mayagüez broad-based and multi-modal program had as its objective to expose students to the following key components of the transportation profession:

- the history and significance of the transportation industry and all modes of travel

- career opportunities in public and private sector transportation, with an emphasis on emerging and new occupational requirements for the new millennium

- various transportations modes, including public transit, automobiles, buses, vans, trains, airplanes, as well as freight, rail, ports, waterways, and pipeline with an emphasis on intermodalism

- advanced technology and intelligent transportation systems, including aviation and space technology

- career options in transportation design, engineering, planning, and research

The overall composition of the program, along with the evaluations administered by the PR-STI staff, helped to determine to what extent the objectives of the PR-STI program were met during the program. 


\section{B. Curriculum Development}

The project team developed a four-week program for the 2001 PR-STI. During this fourweek program, students received:

- Exposure and training through a core curriculum designed to introduce them to the transportation industry and its various modes

- An introduction to a series of academic and practical experiences designed to motivate and encourage them to pursue transportation careers

- Training and exposure to science, mathematics, and technological enrichment through planned educational activities

- Educational field trips and on-site seminars to introduce them to various transportation services and modes

- An opportunity to participate in leadership and other professional activities designed to introduce them to university life and higher educational requirements.

The participating students were expected to:

- Produce a weekly written report summarizing the activities and indicating what did they learn in the process

- Work in groups for several small design and construction projects

- Actively participate in conferences, field trips, workshops, and hands-on projects and any other institute activity

- Develop, with their corresponding group, a final summer research project and, for it, do a written report, an oral presentation, and a poster.

\section{Program}

The students who attended the PR-STI were exposed to a diverse and multimodal set of transportation facilities. Institute participants also gained exposure to research facilities at the University of Puerto Rico, Mayagüez campus. They participated in activities that developed and emphasized the need for technical skills in the transportation profession. Based on the diversity of the PR-STI academic program, including the attention to air, land, and water transportation and the skills needed to pursue careers in these fields, the objectives of the program were met.

\section{List of Activities}

1. Enhancing the Knowledge about Transportation

Building Big Video Series. Lectures were presented on the design and construction of bridges of historical significance to the development of civilization. Our lectures were based on the Building Big documentary series developed by the American Society of Civil Engineers to educate the general public about the accomplishments of civil engineers. The tape related to bridges was chosen for the PR-STI presentation. Before the viewing of the tape, the general concepts were presented. A discussion with the participation of the professors, the tutors, and the students was developed after the tape, which included the theoretical basis for the bridge building competition. 
Introduction to Transportation Systems - The purpose of this topic was to introduce the main concepts of transportation systems, the social objectives of transportation projects, and main activities of the professionals dedicated to the transportation field. Students were introduced to transportation and activities systems, their strong relationship, and the main components of both systems according to the classification used in transportation engineering.

Safety Concerns in Transportation Facilities - Basic principles and issues related to safety in transportation systems were presented. A video on jersey barriers design and function was part of the presentation. The presenter talked about his experience as a consultant for the Department of Transportation and Public Works and the Highway and Transportation Authority.

NASA Presentation - The resource presented research opportunities and jobs in NASA. Highlights on the participation of Puerto Rican professionals in NASA were part of the presentation. The use of satellite technology in multiple applications ranging from space traveling to sea temperature assessment was discussed. NASA material was distributed to the participants

Astronomy: How to get to the Stars - As a complement to the NASA presentation, the presenter explained the interaction between the human race and the science of space. The participants enjoyed this conference due to the neatness on presenting complex concepts in a simple way easy to understand by high school students.

Personal and Professional Experience in Transportation: Teaching and Consulting - The purpose of this topic was to present a live testimony of a professional that has dedicated his life working on several transportation projects, teaching at the university and also interacting with the community through service. In addition, the importance of preserving a healthy family life was presented. The presenter spoke about his experience as a university professor and as a consulting engineer. He spoke also about the advantages of being a university professor and the positive aspects of the transportation profession in general.

An Overview of Traffic Engineering Studies - An engineer presented the basic principles and issues related to traffic engineering studies. He based his presentation on his academic and professional experiences. His presentation focused on the advantages and benefits of traffic counters. A variety of traffic counting procedures and their related characteristics were explained. He used several real-life examples to show the students some of the lessons learned during his years practicing the profession.

Electrical Engineering in the Transportation Industry - A professor of electrical engineering specialized in control systems, made a general presentation on the different areas that encompass this engineering discipline. He explained to the students the importance of electrical engineering in transportation by providing examples of transportation projects where the electrical engineer participates in. He talked about maritime and air transportation. This lecture accomplished a number of objectives 
including presenting the interdisciplinary nature of transportation projects and making the student understand the complexity and high technology nature of modern transportation systems.

Transportation and the Social Sciences - A professor of social sciences with extensive experience in transportation projects, presented to the students the importance of the human being in all engineering projects. This session fulfilled the following objectives: present the interdisciplinary nature of transportation projects, explain what a social scientist can do in the transportation industry, and understand transportation systems as a social system.

What is the FHWA? - An engineer from the FHWA, came to visit and participate in the closing activities of the Summer Institute. He met with the students and presented them the history and role of the FHWA and its interaction with the local transportation agencies. He talked about jobs and internship opportunities with FHWA and about his own experience, first as a student at the UPR at Mayagüez and then as a starting young engineer with FHWA.

\section{Enhancement/Personal Development}

University Tour - The first day of the Institute the participants went on a walking tour through the university campus. The objective was for them to know where they would be going for the different activities and meeting places but also to learn a little about the history of our university and its buildings.

Adjustment to University Life - The Student Ombudsman met with the participants the first day for a session that included an ice-breaking exercise. She spoke about the life of the university student, its challenges, and what to expect.

Library Tour and Lecture on "How to use the Library Resources" - At the Main Library, a librarian gave the students a tour of the facilities and counseled them on the capabilities of the library. She also made a presentation, with several hands-on exercises. She discussed the electronic way to perform a literature search. She briefed them particularly on where to find literature related to the transportation topics they had chosen as their summer projects.

Ingenuity and Creativity - During this interesting talk/workshop, the presenter explored with the students various forms of creative work. First, a short talk including student questions and answers was targeted to open the students' minds towards innovation. They developed their abilities to think and do things with limited resources using their imagination. A case study was also presented to stimulate the use of graphical language (drawing on a poster board) to express their ideas regarding the case presented.

Professional Ethics - The purpose of this topic was to show the importance of ethics in people's life. The presenter gave an overview about the current situation worldwide. She spoke about the distribution of resources and quality of life around the world, 
highlighting imbalances that exist. She also stressed the importance of new leaders that recognize the injustice present in the world and are able to encourage and guide people toward a world with a better sense of justice for everyone. She emphasized the importance of cultivating ethical values

Paths to Success - The objective of this workshop was to explore consciously the student's own strengths and weaknesses in order to apply that knowledge to create a successful future. Students understood how to improve their skills according to the new knowledge about their style of learning, working, and functioning in life.

Creativity, Design and Sustainable Development - This was truly an eye-opener conference that an engineer from Hewlett Packard and former professor, presented to our students. This talk was aimed at orienting the students toward new ideas regarding the use of our resources to provide the transportation services needed for sustainable development. He explained the use, in many cases inefficient, of resources to provide transportation. He also presented alternative sources of energy that are currently in use and some of them in the research stage that can be implemented in the near future. In addition, He presented a live example: a solar car model. Many lessons for the future were learned through this conference. For instance, lessons related to alternative energy sources, and the importance of recycling for a better sustainable world.

How to Integrate Sound, Pictures, and Video on a Presentation - The main topic of this workshop was how to create professional looking presentations using multimedia. They were taught how to capture, modify, and use sound and video into several types of digital files. Students also learned how to incorporate those sound and video digital files into their presentations. Students were able to work in groups with the software that allowed them to explore all the capabilities presented in this interesting workshop.

The use of Photographic Equipment to Document Engineering Projects - The objectives of this topic were to prepare the students to take good pictures, and to help them develop their skills as photographers to clearly document their work. Several topics were covered during this talk, including the use of photography to document engineering projects, the different types of cameras, how to use various types of cameras, film characteristics, composition rules, and general ideas and tricks to obtain good pictures by correctly handling the light, speed, and position.

Effective Report Writing, Oral Presentations, and Poster Design - The objectives were to present the main characteristics of the computer programs used for report writing, poster design, and oral presentations, to introduce the students on the use of the programs, and to provide them with the necessary tools to perform their job on the research project that they had to do as part of the Summer Transportation Institute. In terms of report writing, the discussion included general aspects of writing, software used to write a document, typical table of contents on research reports, sequence of topics covered, and basic rules of writing style. The oral presentation part included general aspects of it, preparation needed, how to obtain and present the main ideas, and basic rules of presentation style. In addition, poster design was discussed. 
The students participating in the PR-STI applied all the lessons learned during this lecture on the development of the research topics prepared.

Web Page Construction - An expert in designing web pages introduced the students to the fascinating topic of web page design and construction. Working in groups of two students, they developed their own web page for the PR-STI. In their page they included their pictures, names, and schools and some phrases or paragraphs that represented their experience during the summer. Web pages were posted in the Civil Infrastructure web site http://ce.uprm.edu.

\section{Workshops and Hands-on Projects}

The objective of the workshops and projects was to enhance the skill of each student in craftsmanship and design and provide experiences of teamwork with various individuals with different views to help them with their professional careers in the future. These projects included: Rocket: Construction, Embellishment, and Launching; Solar Car Race; Bridge: Construction and Testing; Model Airplane: Construction and Testing; and Model Catamaran: Construction and Testing.

\section{Field Trips}

The field trips were designed to expose our students to the different modes of transportation. The students had the opportunity to see first hand the different modes and evaluate their advantages and disadvantages. The students understood through the field trips the importance of a well integrated multimodal system of transportation. Another benefit of the field trips was the interaction the students had with the professionals as well as the fun associated with being outdoors. A description of each of the field trips is presented herein.

PR-10 Highway Project - Attendance to this field trip included all the professors and student mentors and a specialist in geotechnical engineering. This experience helped the students understand the construction of a road through mountain terrain and the diverse problems encountered in this type of construction. The expert gave a basic view of what a geotechnical engineer does and how he has to use judgment and experience to face each situation that occurs. The students were also able to see a road that has been severely damaged and closed down due to unforeseen natural factors, and an estimate of time and construction cost that are invested in this type of project.

Lake Dos Bocas Ferry and Transportation Enhancement Project - The Lake Dos Bocas project was developed for the residents of the Dos Bocas area who lost their roadway transportation due to the creation of a manmade lake. The students were able to use the ferry transportation system and view the area of the lake and how the ferry transportation system works. A conference was given by the Department of Transportation and Public Works (DTPW), on the usage and purpose of the ferry transportation system as well as other non motorized transportation projects that are being developed in P.R. 
Metropolitan Bus Authority (MBA) - This visit helped the students visualize and understand how the Metropolitan Bus Authority conducts its operations and services. Personnel from the MBA guided the students through control rooms as well as maintenance areas to see how the operations were conducted on an everyday basis. The staff also explained how new services and technologies are going to be introduced in the near future and their benefits to society.

Tren Urbano Tunnel Construction Site - This trip included a tour of the Río Piedras tunnel construction site that is part of the Tren Urbano project in the San Juan Metropolitan Area (SJMA). The students were taken down to the tunnel and were able to walk and see the construction site. The students also learned about construction techniques used in this project and problems encountered at each stage, as well as the emphasis on safety at construction areas. The students were also reminded on the importance and necessity of an efficient transportation system in P.R. and how the Tren Urbano will serve as a spinal chord for the public transportation system in the SJMA.

An Intermodal Experience: Riding Bus, Público (Jitney), and Ferry - This experience provided each student with the unique experience of utilizing all the components of the mass transit system in San Juan, P.R. MBA routes were used from a bus stop near the hotel in Carolina to get to San Juan. Then they made a transfer to another bus towards Bayamón where they boarded público cars (jitneys) to reach the ferry terminal at Cataño. The ferry took them to Old San Juan where another MBA bus was taken to get back where it all started. The students interviewed some of the users of those different modes of transportation for their final presentations.

Luis Muñoz Marín International Airport - This trip included various presentations from several airport authorities such as the airport manager, operations manager, and tower control director as well as other government officials from the port authorities. These presentations included job descriptions as well as practical aspects from each job and challenges faced on an everyday basis. This trip also included a tour to some airport hangars and the runway.

Puerta de Tierra Transit Control Center and ITS Project - This visit stressed the operation and importance of ITS technologies in transportation, as well as how the ITS control center is operated and its benefits to the roadway users in P.R. The Executive Deputy Director for Transit of the P.R Highway and Transportation Authority, gave a presentation on how this control center was created and how it is operated. Visual aids and actual examples of how and when this technology is used as well as some costs involved when using this type of technology were presented. 


\section{GROUP TECHNICAL PROJECT}

\section{A. Project Objectives}

To recognize that the study of transportation systems is one that is broad and extensive, where professionals of diverse areas of expertise interact and where different existing modes can be studied and analyzed using the principles of Transportation System Analysis as seen in class.

\section{B. Project Description}

Considering that there are diverse modes and means of transportation that are operational on the Island and others that are in the stage of construction or planning. In this project students learn the diverse systems and use the concepts presented in the conferences to describe one of them in detail. The work is done in groups. The selection of the mode was discussed in class.

Students were asked to describe the physical component of the transportation system in the actual situation or planned for the selected mode. In their description, they should use all the concepts presented in the conferences. They should include detailed description of technology, network, links, vehicles, operation policies and organizational policies. In addition, students should provide a detailed description of the socio-physical component of the activity system in the actual situation or planned by the selected mode. Students were also asked to present an international system (in another city or country) that is similar to the one studied in this project.

\section{Project Development}

The following tasks were presented as part of the group project. The group project provided the students with the challenge of creating and developing their own ideas through a solution of a problem in a collaborative manner.

Group Slogan and Logo Development - Each group created artistically a group slogan and logo for parent's visitation day on the final day of the institute.

Research and Project Development - Each group was given time to look for information through the library, internet, interviews as well as other types of documentation for their final reports. Once the data was obtained each group proceeded to work on their oral presentations for the final day of the institute.

\section{Presentation of Results}

Each group did a written report, an oral report, and a poster. The rules for the presentation of the report were posted on the Internet at the following address: http://ce.uprm.edu/antonio.

Poster Design - With the information gathered, each group created a poster of their oral and written reports. These posters showed the different activities that the students performed during the month of this institute and the lessons learned from this program. 
Oral Presentation - The final day of the institute each group gave their oral presentation to several federal and state authorities; as well as professors from the U.P.R. and some parents, explaining their topic in detail. This resulted in a hands-on experience on how to give oral presentations and becoming better professionals in the future.

\section{SPORTS AND RECREATION}

\section{A. Program Objectives}

The PR-STI staff noticed very early in the process the importance of incorporating sport activities in the program even within a non-residential format. The objectives were:

- To get to know each other under a setting different from the classroom

- Enjoy the splendid summer weather

- Allow the students to burn some energy in the field

- Have fun

- Strengthen soul, body and mind

\section{B. List of Activities}

Frisbee Football, Pool and Basketball, Pool and Recreation at the Hotel, Visit Paseo Piñones - Enhancement Project for Bikes and Pedestrians, Visit the Puerto Rico Art Museum, and Visit Las Cascades Water Park

\section{GRADUATION CEREMONY}

The PR-STI staff organized and hosted a graduation ceremony for the PR-STI participants, held on Friday, July 20, 2001, at the University of Puerto Rico, Mayaguiez Campus. Transportation professionals, university administrators, along with family and friends were invited to attend the ceremony which was preceded by a lunch.

The Chancellor of the University of Puerto Rico at Mayagüez, Prof. Pablo Rodríguez, and the Dean of the School of Engineering, Dr. Ramón Vásquez, addressed the audience and handed in the certificates and the various awards to the participants.

\section{EVALUATIONS}

The project team gave the students evaluation forms at the beginning of the four-week institute as required. The forms provided the attendees with the opportunity to provide feedback on the speakers, field trips, activities, staff, and overall program. The intent was to identify those activities that were especially effective and enjoyable to the students and those that might need improvement or alteration in future institutes. The following sections provide a brief summary of the evaluation forms completed by the PR-STI participants. 


\section{A. Speakers}

The attendees indicated if the speakers provided clear and interesting information and felt that they learned something new about transportation careers through the various presentations. In the student's opinion, the speakers were responsive to questions and were excited about the PR-STI program.

\section{B. Field Trips}

The PR-STI participants strongly agreed that the various field trips they took were informative, interesting, and provided realism to the topics covered by the speakers. They also believed that the number of field trips they took was appropriate.

\section{Activities}

The PR-STI participants responded that the project activities on which they worked during the program helped them understand the technical topics and gave practical experience related to transportation. They agreed that the time allowed for the activities was adequate. They suggested more competition between groups in the future.

D. Staff

In general, the PR-STI students believed that the project staff was very committed to their awareness of transportation careers. Staff was helpful, available when students had questions, and had a good attitude towards academic excellence. Furthermore, the students believed that the staff members were friendly and encouraging throughout the course of the program.

\section{E. Overall Program Evaluation}

The students indicated that the number of field trips and activities were appropriate and relevant to the program. They also confirmed that the program included field trips to all transportation modes available. The students also agreed that the program was fun, educational, and that they would like to return if the program was offered again. Overall, the participants rated very positively the 2001 PR-STI program. The results of the general evaluation are summarized in Figure 1. 


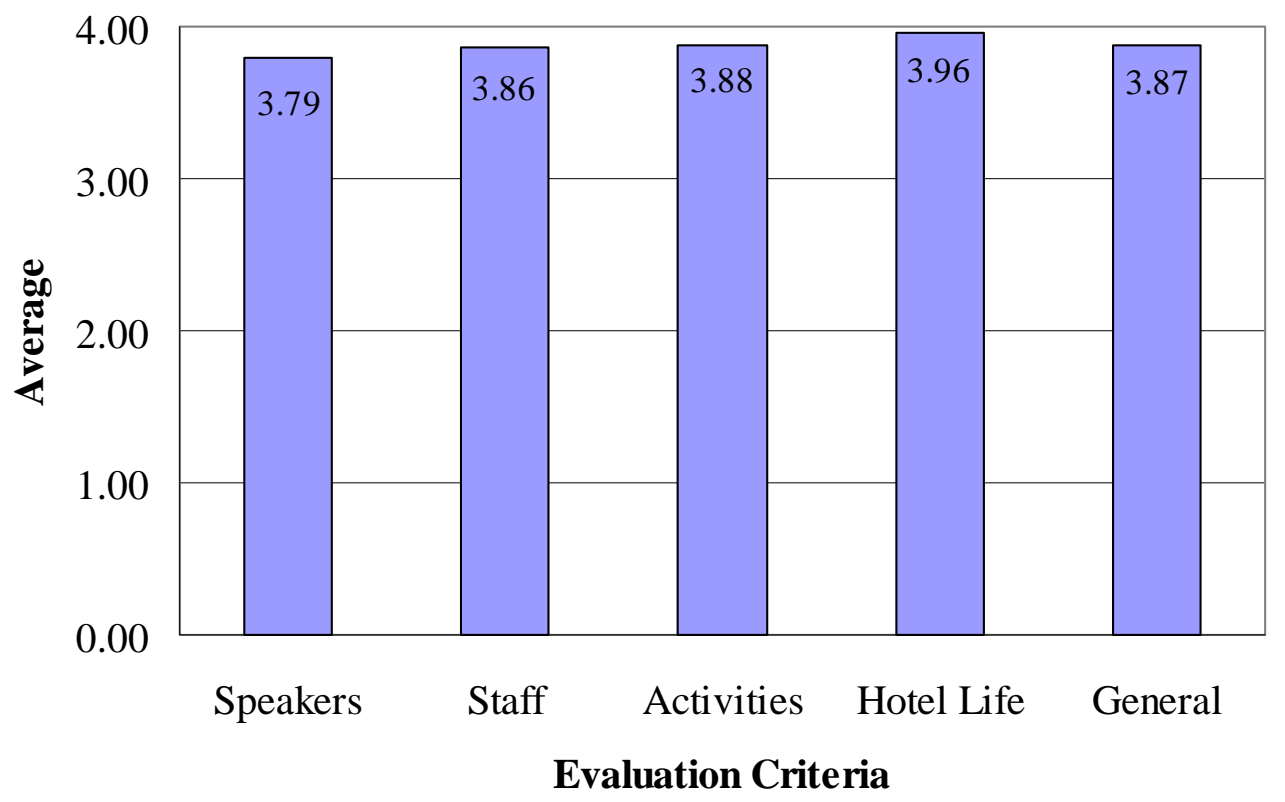

\section{Figure 1. Overall Program Evaluation}

\section{PARTNERSHIPS}

The University of Puerto Rico at Mayaguiez worked to secure support from the transportation community for the PR-STI program. This support took on many forms, including the recruitment of student participants, the support of advisory board members, the provision of speakers, travel expenses for speakers, the coordination and provision of technical tours of facilities, direct financial support, the provision of transportation for the students, and other inkind giving.

\section{FINAL REMARKS}

It is the opinion of the 2001 Puerto Rico Summer Transportation Institute staff and, more importantly, of their participants, that this year's program was a complete success. The project team met the goals and objectives of the program. The 20 students who attended the institute were exposed to the gamut of career opportunities within the transportation industry and had the opportunity to gain hands-on technical experience and networking with professionals to learn more about career choice.

We feel that for our first experience in conducting a summer transportation institute, the support obtained from a number of very helpful friends of our university was very rewarding. It should be noted also that our own personnel, including our students and the staff of the Civil Infrastructure Research Center, worked very hard and beyond the call of duty. This sense of doing things right and not objecting to long hours assured the success of the institute.

We contacted a number of public agencies and received from them support to carry-on the activities we had planned for the institute. These agencies responded as partners to this 
endeavor. For next summer's institute, we will continue our efforts in obtaining funds and support from the private industry and the various agencies of the federal and local government in order to secure a successful continuation of the job started in 2001.

\section{ACKNOWLEDMENTS}

We express our sincere gratitude to all those who contributed in one way or another to the successful completion of the first Puerto Rico Summer Transportation Institute. Very special thanks are due to Dr. Clarence Hill, Director of the National Summer Transportation Institute and Joel Washington of the Federal Transit Administration for motivating us to participate in this most rewarding project.

This project was conducted at the UPR Mayagüez with support provided by the university and by the US Department of Transportation, and it's Federal Highway Administration through the National Resource Center at South Carolina State University.

\section{BIBLIOGRAPHIC INFORMATION}

1. Federal Highway Administration, USDOT. 1999 National Summer Transportation Institute National Resource Center Final Report. Report Number FHWA-CR-01-002. Washington, D.C.

2. Anderson-Rowland, Mary R., Reyes, María A., Jordan, Cathryne and McCartney, Mary Ann. (1999). "Model for academia, industry, and government collaboration for K-12 outreach." $29^{\text {th }}$ Annual Frontiers in Education Conference: Designing the Future of Science and Engineering Education. San Juan, Puerto Rico. V3, p 13a7-2 $13 \mathrm{a} 7-7$.

\section{BIOGRAPHIC INFORMATION}

ANTONIO A. GONZÁLEZ-QUEVEDO, PH.D. He is a Professor of Civil Engineering and Director of the Civil Infrastructure Research Center of the University of Puerto Rico at Mayagüez. Dr. González-Quevedo has been involved in a number of programs related to professional development of minority students from high schools and colleges. His teaching and research interests lie in the area of construction engineering and management.

DIDIER VALDÉS-DÍAZ, PH.D. He is an Assistant Professor of Civil Engineering at the University of Puerto Rico at Mayagüez. Dr. Valdés-Díaz teaches undergraduate and graduate courses in transportation engineering. He has participated in several research projects and also in educational projects to encourage minority students to pursue graduate degrees in engineering. He directs the Summer Transportation Institute in Puerto Rico.

FREYA M. TOLEDO-FERIA, M.S. She is an Assistant Professor of General and Industrial Engineering at the University of Puerto Rico at Mayagüez. Professor Toledo held a high government position in the Department of Transportation and Public Works planning and implementing various public transportation systems in the San Juan Metropolitan Region. She supervises the academic program of the Puerto Rico Summer Transportation Institute. 